\title{
Geographical variation and factor associated with modern contraceptive utilization among Young married women aged between 15-24 years: Spatial and multilevel analysis of EDHS 2016.
}

Kedir Abdu Yesuf ( $\nabla$ abdukedirkapbc@gmail.com )

Dessie Health Science College

Ayesheshim Muluneh Kassa

Dessie Health Science College

Eueail Teferi Asrese

Dessie Health Science College

Research article

Keywords: Contraceptive, Ethiopia, Multilevel, Spatial, Young married women

Posted Date: October 8th, 2020

DOl: https://doi.org/10.21203/rs.3.rs-55326/v3

License: (c) (i) This work is licensed under a Creative Commons Attribution 4.0 International License.

Read Full License 


\section{Abstract}

Introduction: Despite increase in trend of modern contraceptive use in worldwide it was still low in developing country. In Ethiopia modern contraceptive utilization among young married women was low which shows gaps between women reproductive desire to avoid pregnancy and contraceptive behavior. This study showsvaration in modern contraceptive utilization and factor associated with it among young merried age group between 15-24 years in Ethiopia.

Objective: The aim of the study was to assess the geographical varation of modern contraceptive utilization and associated factor among young married women aged between 15- 24 year in Ethiopia.

Methods:In this study cross-sectional study design was conducted using Ethiopia demographic and health survey 2016 data. The sample size was 2298 young married women aged between 15-24 years.Geographical variation assessed by Spatial analysis using spatial autocorrelation Moran's I, GettisOrdGi* and spatial scan statics to identify significant clusters of modern contraceptive utilization among young married women. Determinant factor for modern contraceptive use were analyzed using a two levelmixed-effects logistic regression model which include both the individual and community level factors.

Result: In Ethiopia, prevalence of modern contraceptive utilization among young married women age group between $15-24$ years was $36.7 \%$. Geographical varaition asessed by spatial scan statistics identified primary clusters of modern contraceptive utilization were all zone of Amhara, Addis Ababa and Shewa. In other hand,Gettis-OrdGi* analysisindicated zone 1 of Afar region, Borena zone of Oromia region and all zone of Somalia regions were low prevalencespot region. In this study religion, respondent working status, number of living children, husband desire more children, region, community mas media exposure and community educational level were statically significant variables for modern contraceptive utilization among young married women.

Conclusions: There is low prevalence of modern contraceptive utilization among young married women and it was varied across zone of Ethiopia. High and low prevalence spot area, most likely cluster, community and individual level factor associated with modern contraceptive utilization is identified which is important to prioritize family planning strategythat focus particularly for young population segment. Therefore, exerting much effort on all of this area is supreme important as it has significant public health contributions.

\section{Background}

Family planning encompass many area defined as "the capability of individuals and couples to anticipate and attain their desired number of children, and the spacing and timing of their birth, which is achieved through the use of contraceptive methods" (1). Family planning is important because it is cost-a effective way to reduce maternal mortality by reducing the number of pregnancies, abortions, proportion of at high-risk births, improve health related outcome, and social and economic benefits (2). 
Globally, $28 \%$ of young married women lived in developing regions. Most of them was from sub-Saharan Africa estimated $20 \%$ of $15-19$ year old adolescents and $60 \%$ of $20-24$ year old young adult women are married one $(3,4)$.Intervention during young age is very effective since young adulthood is an important period for physical and mental development that would have long term implications. Additionally young married women face many challenge related to reproductive health. Therefore to overcome this challenge it is critical to accesscomprehensive reproductive health serviceswhichfocus on safe, healthy sexual and reproductive lives $(5,6)$.

Modern contraceptive utilization among younger married women was low when compared to older women (7).It is higher amongst sexually active unmarried women age 15-24 than married peers. These young married women had higher risk of unintended pregnancies because of repeated pregnancy, lower educational attainment, higher rates of contraceptive failure and more likely to abandon contraception(8, 9). Unwanted pregnancy would have consequences of unsafe abortion, maternal and infant morbidity, dropping out of school, unemployment opportunities and increase the risk of poverty(10). Barriers to use modern contraceptive among young married women include poor understanding of pregnancy risks, gendered social norms, and concerns about the effect of contraceptives on health or fertility, opposition from partners, cost and disapproving attitudes from providers $(11,12)$.

In developing country little published evidence about married young womenand their partners to address the social and behavioral constraints to contraceptive use. So it is important to learn from the few rigorously documented and evaluated projects that have worked with married young women (13). Overall, only $52.9 \%$ of the women in were using a modern contraceptive method globally, but coverage varied greatly. In West \& Central Africa showed the lowest coverage; whereas South Asia, Latin America \& the Caribbean had the highest coveragemodern contraceptive utilization(14).

In Ethiopia young aged 10-24 comprise $35 \%$ of the country population, $28 \%$ of adolescents aged $15-19$ and $24 \%$ of young women aged $20-24$ have had unintended pregnancies $(27,28)$. One in 10 young women age 15-24 have a unmet need for family planning(1). However trend of modern contraceptive prevalence among young married women increased from 6\% in 2000 to $36 \%$ in 2011(15)

Women especially those young ages group their decision influenced by community and environment so this population segment do not live in isolation. While women may receive accurate health information from facility and health providers but health-seeking decisions are influenced by others. Younger married women were challenged by partner and family involvement in decision making on using of Family planning method (16).

Young sexual and reproductive health is affected by a country's cultural, religious, legal, political and economic contexts. Utilization of family planning methods is determined by factors at the individual, household, and community level, but the geographic pattern of contraceptive use may be associated with influences at zonal level such as the availability and accessibility of health services in these areas(17).In responding, health actions are needed at each level, from structural, through community settings including schools and health services (18-21). 
Global effort has been implement to increase modern contraceptive utilization which can contribute to achievement of national and global goals and priorities, such as Family Planning 2020 and the Sustainable Development Goals. Access to sexual and reproductive health services for youth and improving availability, affordability, and youth-friendliness of service may critical for this achievement. But it is not enough which need to include provide service in different location by private and governmental provider to offer quality of service but also emphasized the important of policymakers concerned with youth FP programs (21-23).

Ethiopia actively developing strategies to expand family planning (FP) access for young people as all Family Planning 2020 (FP2020) commitment-making countries have a focus on youth, including through provision of youth-friendly services, free contraceptives for adolescents, and ensuring consistent commodity supplies to youth-specific facilities (23). But the growing number of young people, renewed interest in FP service, multi-component programming by engaging parents and community leaders and training health care providers were continuous issue need to focus by policy maker. In addition, more evidence is needed on other approaches designed to reach young people, including providing services outside of health facilities, such as pharmacies and drug shops, determining how to reach the most vulnerable adolescent groups, and developing standardized $(6,24,25)$.

To implement this there is need to have evidence about distribution modern contraceptive utilization across zone of country among young married women, and individual and community level factor association with it. So this study assessed the geographical variation of modern contraceptive utilization, and individual and community level factor association with it among young married women aged between 15-24 years evidence from Ethiopia demographic and health survey 2016. Additionally this research focuses on young married women because young married women are under intense pressure to demonstrate their fecundity.

\section{Methods And Materials}

\section{Study design}

Study design was population based cross-sectional study conducted on Ethiopia demographic health survey (EDHS) 2016. Generally, EDHS 2016 was collect data from the nine regions and two administrative cities of Ethiopia. Ethiopia demographic health survey data was collected from January 18-June 27, 2016(26).

\section{Study area}

The study was done in Ethiopia located in $3^{0}-4^{0} \mathrm{~N}$ and $33^{0}-48^{0} \mathrm{E}$, and situated at the eastern tip of Africa. Ethiopia is one of the tenth largest countries and second populous country in Africa. The population of Ethiopia estimated 110, 815,010 in 2019 fromprojectionsof 2007 population and housing census. In the country, there are nine regional states and two city administrations subdivided into 68 zones, 817 districts and 16,253 kebeles.Majority of the population in country (83.6\%) are living in rural areas and the average 
household size is 4.7 persons. In addition, women child bearing age constitute $24 \%$ of the population. Health facility including 7,685 health posts, 392 hospitals and 3,962 health centers have been giving health care services and all health facilities provide family planning service at least five days a week (27, 28).

\section{Data source and extraction}

The data for modern contraceptive analysis were extracted from EDHS 2016 and accessed from the Measure DHS website (http://www.dhs program.com). This study conducts secondary data analysis from nationwide community-based survey. The data sets were downloaded from DHS website in SPSS and STATA format with permission from Measure DHS website (http://www.dhs program.com). STATA software was used to cleaning and recording downloaded dataset. The modern contraceptiveutilization related datasets were joined to Global Positioning System (GPS) coordinates of EDHS using the joining variable as recommended by DHS measure. EDHS surveys samples were selected using a stratified twostage cluster design (26).

\section{Outcome variable}

Modern contraceptive utilization among young married women is outcome variable for this study. Modern contraceptive use defined as current use of a modern method includingpill, intrauterine device, injections, male condom, female sterilization, periodic abstinence, withdrawal, implants/Norplant, lactationamenorrhea, emergency contraception, standard day's method.It derived from variable recorded as "Current use by method type" in EDHS which categorize as "no method", "using modern method" and "using traditional method". In this study modern contraceptive use categorized as a binary outcome of use of modern method was assigned "yes" (coded as 1) and not using modern methodincludingtraditional method was coded as "No" (coded as 0 ).

\section{Explanatory variables}

The predictor variable for modern contraceptive utilization among young married women include both individual and community level characteristics.

\section{Individual level variable}

Individual level variable include age (coded as 15-19 and 20-24), age of cohabitation (recode as $<18$, $\geq 18$ ), education (coded as no education, primary, secondary and higher), wealth quintile (coded as poorest, poorer, middle, richer and richest ), religion (recoded as Orthodox ,Muslim, Protestant and other) ,number of living children (recoded as $0-1,2-3$ and $>3$ ), partner education(coded as no education, primary, secondary and higher), respondent working status(code as yes and no) and partner occupation (recode as no,service, agriculture,manual andother). Knowledge about family planning,heard family planning message which defend as respondent heard about family planning (radio, TV or newspaper/magazine), heard FP in community events,field workers visit in last 12 month and health facility visit within 12 months(coded as no and yes). Perception of distance from health facility(code as no big problem and big 
program), desire more children (coded as have another, undecidedand no more), husband desire more children (coded as both want same, husband wants more, husband wants fewer, don't know) and decisions maker for family planning(recoded as mainly respondents, mainly husband and Joint decisions).

\section{Community level variable}

Influence of community level factor on reproductive health particularly on contraceptive utilization was examined by previous studies $(18,29,30)$.Community level variables for this study were computed by aggregating the individual characteristics in a cluster since EDHS did not collect data that can directly describe the characteristics of the clusters except place of residence and region. The aggregates were generated using proportion of a given variables subcategory within given cluster. Then allaggregate value categorized into groups based on the national median values since computed value is not normally distributed.

Community level of poverty was created by aggregate individual wealth index by cluster. We categorize women living in cluster having less than $50 \%$ poorwomenas low poverty clusterand cluster having greater than $50 \%$ of poorwomenas high poverty cluster.

Community level of health service utilization: the proportion of health service utilization generate by aggregate women who had visited health facility in the past 12 months by cluster. Cluster having $<50 \%$ visited health facility as low health service utilization and cluster having $>50 \%$ visited health service as high utilization.

Community distance to a health facility generated by aggregate those report distance to a health facility was a big problem to get medical help, and categorized as big problem and no big problem.

Community women education level was created by aggregate women educational level by cluster. Cluster having less than $50 \%$ of educated women categorize as low educated clusterand cluster having greater than $50 \%$ of educated women as high educatedcluster.

Community mass media exposure was generated by aggregateexpose to one of mass media (radio, TV ormagazine).Cluster more than $50 \%$ respondent expose to mass media was taken as high exposedclusterotherwise it taken as lowexposecluster.

Place of residence (coded as rural and urban) and region that included nine regions and two administrative cities (code as Adiss Ababa, Tigray, Afar, Amhara, Oromia, Somali, Benishangul-Gumuz, SNNPR, Gambela, Harari, Addis Ababa, Dire Dawa)were already considers as community level factor in DHS.

\section{Sample size determination and sampling procedures}


Ethiopia demographic and health survey 2016 select 18,008total households at response rate of $98 \%$. About 16,583 eligible women identified for individual interviews from total of household size of 16,650. Individual women interview completed with 15,583 womenage between 15-49 years yields a response rate of $95 \%$. Sampling weight were applied on individual interview and final sample size were 10,223 (weighted sample) but only 2298 young married women (weighted sample) age between 15-24 years were included in this study (26).EDHS employed using two-stage samples technique that stratified based on geographic region and urban/rural areas. Primary sampling units (PSUs) were selected in first stage with probability proportional to size (PPS) within each stratum. The PSU forms the survey cluster a total of 645 Enumeration areas including 202 in urban areas and 443 in rural areas. Then in second stage of survey fixed number of 28 households (25-30) per cluster was selected with an equal probability systematic selection from the newly created household listing. In EDHS 2016 survey overall probability of household selection was differed from cluster to cluster (26).

\section{Population and outcome measurement}

In EDHS, Women aged 15 to 49 were randomly selected enumeration areas (EAs) were eligible for family planning as part of this those all young married women age 15-24 years were included in this study. Modern contraceptive utilization categorized as modern contraceptive utilization and none modern contraceptive utilization.

\section{Data management, data processing and analysis methods}

Sampling weight was applied to an individual interview unit of analysis of young married women age between 15-14 years. It adjustssample for differences in probability of selection and interview between cases in a sample due to design, happenstance or corrections for differential response rates. Since EDHS samples were not self-weighted it need weighted with the available sample weight factor (v005/1,000,000) within the EDHS dataset to minimize the effect of sampling bias.Special codes included in dataset careful considered when analyzing DHS datasets

In DHS missing value were coded as 99, 999, 9999 and it was managed by excluded it from both the numerator and the denominator, by calculate in separate category for percent distribution and leave as it if data is not affected in some variable(26). When the level of missing is relatively large $>10 \%$, the variable should be exclude from regression. However, the bias is always found to be negligible if missing value was less than $<10 \%$. The data extraction, descriptive and summary statistics were done by using STATA 14 version software. Spatial statics part of model was analyzed by using ArcGIS version 10.3 and Sat Scan ${ }^{\mathrm{TM}}$ version 9.6 software.

\section{Spatial analysis of modern contraceptive utilization}

\section{Spatial autocorrelation}

Moran's I is one of spatial autocorrelation method that used to assess the extent of clustering of modern contraceptive utilization among young married women age between 15-24 years in the regions. Moran's I 
test statistic computed to test the null hypothesis which state no significant clustering of modern contraceptive utilization in the entire study region (31).

\section{GetisOrdGi* statistic (Hot spot analysis)}

Hotspot statistic was one of local statics used to measure how spatial autocorrelation varies over the study location by calculating $\mathrm{Gi}^{*}$ statistics for each area. Hotspot statistic gives Z-score thatindicate the statistical significance clustering of modern contraceptive utilization, and $p$-value computed to test significance of each value. If the value of $z$-score is in range between -1.96 and +1.96 , the $p$-value would be insignificant $(p>0.05)$ and fail to reject the null hypothesis; this pattern shownas result of random spatial processes. In other hand if z-score falls outside the range, the observed spatial pattern is probably too unusual to be the result of random chance, and the p-valuewould be small to reflect this. Therefore, it is possible to reject the null hypothesis and proceed with figuring out what might be causing the statistically significant spatial pattern of modern contraceptive utilization among young married women. So high Gi* indicates "high prevalence spot" whereas low Gi* means a "low prevalence spot" $(32,33)$.

\section{Spatial scan statistic}

Spatial scan statistic was analyzed based on Bernoulli model. Bernoulli model was applied by Kuldorff using the SaTScan ${ }^{\text {TM }}$ software to analyze the purely spatial and clusters of modern contraceptive utilization among young married women age between ages 15-24 years. A Bernoulli-based model analyzed events at particular places if married young women usemodern contraceptive or not represented by a $0 / 1$. A spatial scan hasdifferentscanning window (the population at risk) in the shape of a circle, which moves across the study region. In this study spatial scan window was adjusted to $50 \%$ to encompass small Custer. It examined a large number of distinct geographical windows for the presence of modern contraceptive utilization among young married women age between 15-24 years. As result each window of study region used Monte Carlo simulation to test the null hypothesis that state there was no statistically cluster of modern contraceptive utilization cases within the window.

The cluster ranked primary and secondary cluster based on likelihood ratio test statistic. The greatest maximum likelihood ratio was considered as the primary cluster of modern contraceptive utilization. Secondary cluster of modern contraceptive utilization weresignificant clusters that did not overlap with the primary cluster $(31,34)$.

\section{Multilevel logistic regression analysis}

The predictor of modern contraceptive utilization was identified by using multilevel logistic regression model. Those individual and community level variables with P-value $<0.2$ in bi-variable logistic regression model were entered into multivariable logistic regression model to measure the effect of each variable after adjusting for the effect of other variables. Individual and community level variables with $p$-value < 0.05 were considered as statistically significant to identify independent factors for modern contraceptiveutilization among young age group between 15-24 years. Multivariable logistic regression 
model demonstrate the importance of the community level and individual level component by estimated fitted models(35).

Multilevel logistic regression analysis is appropriate to measure DHS data since it is hierarchical data therefore two stage multilevel analyses was used to explore factors affect modern contraceptive utilization among young married women at individual and community level factor(36). Four models were considered in the multilevel logistic regression analysis; model one empty without explanatory variable that specified only the random intercept and it presents the total variance in modern contraceptive utilization among clusters, model two adjusted for individual level variable, model three for adjusted community level variable and model four both adjusted individual and community level variable.Odd ratio measurethe association of modern contraceptive utilization with individual and community levelvariable. In Multilevel logistic regression measurement of variation wasidentifying using interclass correlation (ICC) and proportional change in variance (PCV).Multilevel logistic regression model fitness would be diagnostics by using Deviance Information Criteria (DIC) or Alkaile information criteria (AIC). Final model with lowest AIC and highest log likelihood test was selected as best model to identify factor associated with modern contraceptive utilization. Log likelihood test was considered as better test over AIC since DHS was nested data type(36, 37).

Multicollinearityof both individual and community level variable checked by using Variance Inflation Factor (VIFs) to identify correlations between variables,and determines the strength of the relationships.Variance Inflation Factorexamined instability of effect size of predictors as the result of high collinearity among the factors.VIF of allvariable was assessed by using cutoff value of 10 . If VIF of each variable was less than 10 , it would be included in the analysis (35).

\section{Ethical consideration}

DHS dataset was obtained by registration on the DHS website (www.dhsprogram.com) and getting approval from the measure DHS.Prior to the actual interview, informed consent was obtained from the participants, their guardian or household heads.Data was used in this study only for the purpose of statistical reporting and analysis, and for the proposed research project. The data downloaded from DHS website treated as confidential, and no effort should be made to identify any household or individual respondent interviewed in the survey. Ethical clearance was obtained from the institutional ethical review board of the Institute of Ethiopia public health association, Ethiopia.

\section{Results}

\section{Socio demographic characteristics}

A total of ( $\mathrm{n}=2298)$ young married women age between 15-24 years were interviewed in 2016 EDHS. Among those young married women 1815 (79.47\%) were cohabitation before age of 18 years.About half of the respondent $1158(50 \%)$ were not educated. About $1424(62 \%)$ of respondents had more than one or 
two children. Large proportion of respondents 1745 (76\%) hadn't any work. Regarding to partner's education level, 1355(59\%) were not educated (Table 1).

ble 1: Socio demographic characteristics of young married women in EDHS, $2016(n=2298)$. 


\section{Age}

\begin{tabular}{lll}
\hline $15-19$ & 588 & 26 \\
\hline $20-14$ & 1710 & 74
\end{tabular}

Age first cohabitation

$<18$

1815

79

$>18$

483

21

Women education level

\begin{tabular}{|c|c|c|}
\hline No education & 769 & 34 \\
\hline Primary & 1158 & 50 \\
\hline Secondary & 276 & 12 \\
\hline Higher & 95 & 4 \\
\hline \multicolumn{3}{|l|}{ Religion } \\
\hline Orthodox & 888 & 39 \\
\hline Muslin & 871 & 38 \\
\hline Protestant & 466 & 20 \\
\hline Other & 73 & 3 \\
\hline \multicolumn{3}{|l|}{ Wealth index } \\
\hline Poorest & 481 & 21 \\
\hline Poorer & 561 & 24 \\
\hline Middle & 514 & 22 \\
\hline Richer & 401 & 18 \\
\hline Richest & 341 & 15 \\
\hline \multicolumn{3}{|c|}{ Number of living children } \\
\hline No child & 645 & 28 \\
\hline One-two & 1424 & 62 \\
\hline Three-above & 229 & 10 \\
\hline \multicolumn{3}{|c|}{ Partners education } \\
\hline No education & 732 & 32 \\
\hline Primary & 1031 & 45 \\
\hline Secondary & 363 & 16 \\
\hline
\end{tabular}




\begin{tabular}{|c|c|c|c|}
\hline Higher & 154 & 6 & Family \\
\hline Don't know & 18 & 1 & planning \\
\hline \multicolumn{3}{|c|}{ Respondent working status } & knowledge and \\
\hline No & 1745 & 76 & characters of \\
\hline Yes & 553 & 24 & Young married \\
\hline \multicolumn{3}{|c|}{ Partner occupation } & women \\
\hline No & 145 & 6 & Almost all of \\
\hline Services & 395 & 18 & respondent \\
\hline Agricultural & 1355 & 59 & $\begin{array}{l}2265(98.58 \%) \\
\text { had family }\end{array}$ \\
\hline Manual & 230 & 11 & planning \\
\hline Other & 152 & 6 & knowledge and \\
\hline
\end{tabular}

of respondents 1460 (64\%) discussed FP issues in the community. About 1682 (73\%) respondents heard about family planning by mass media. More than half of respondent $1296(56 \%)$ and 1969 (86\%) were difficult to access health facility and prefer to have another child respectively (Table 2).

Table 2: Family planning knowledge and other characters of young married women in EDHS, 2016 


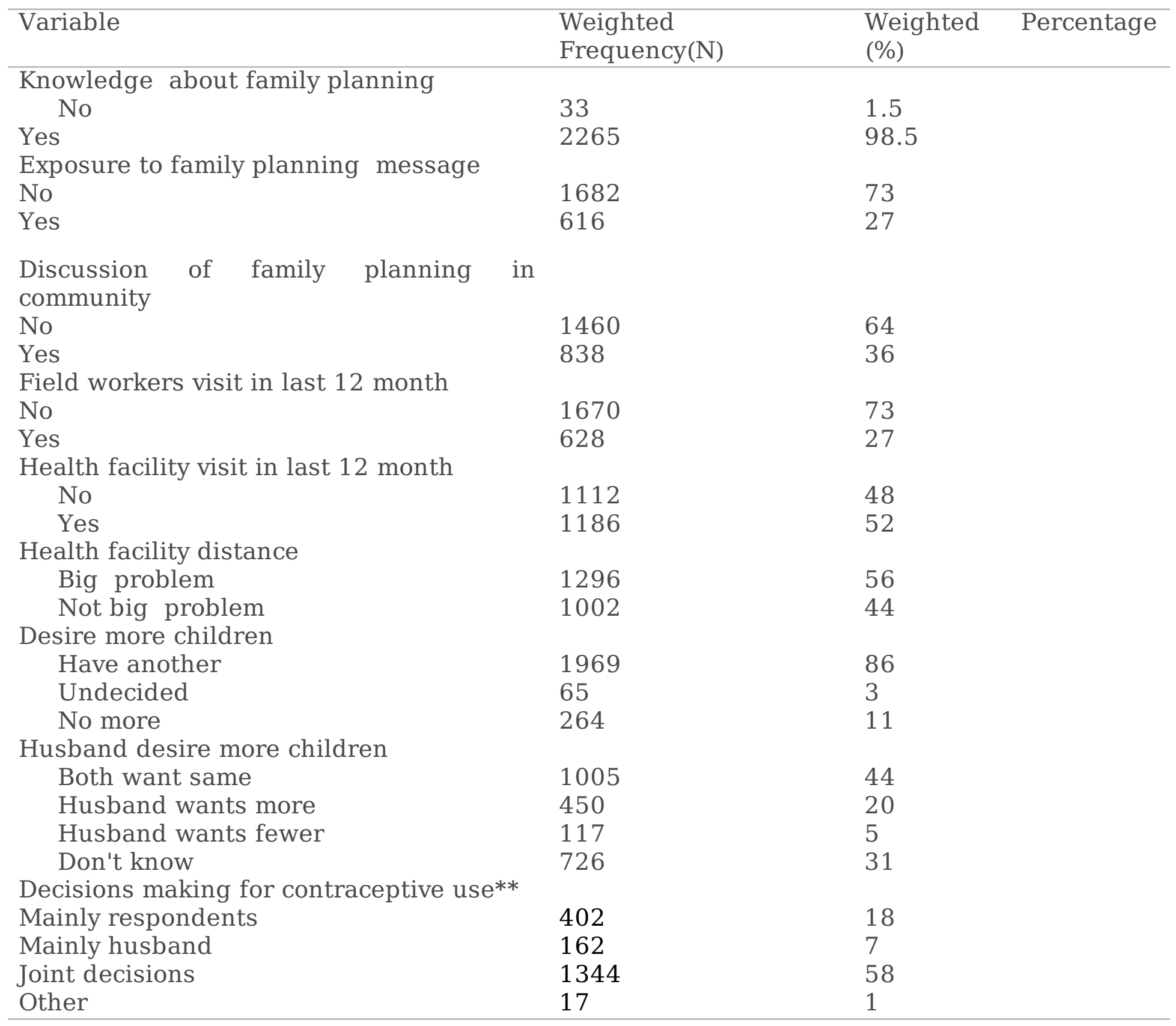

**372(16.2\%) missing decisions for using contraceptive

\section{Modern contraceptive utilization by individual level and community level characters}

Out of the 2298 participants, $845(36.7 \%)$ of young married women respondent had modern contraceptive utilization. About $578(68 \%)$ and 575 (68.0\%) of modern contraceptive utilization were respondents who had child one or two and no working status respectively. Those young married women age between 15-24 years who desire more children and joint decision about contraceptive had 736 (87\%) and 642(76) modern contraceptive utilization (Table 3). In EDHS2016, total of 645 clusters were included but in this study 605 clusters were included in which all young married women age group of 15-24 had lived. More than half $1546(64 \%)$ young married women were in higher proportion of educational level. Most of modern contraceptive user $653(77 \%)$ were rural residence (Table 4). 
Table 3: Bi-variable multilevel logistic regression of modern contraceptive utilization, and socio-demographic and other characteristics in EDHS, 2016 
Characters

\section{Age}

\begin{tabular}{l} 
Age \\
\hline $15-19$ \\
\hline $20-24$ \\
Age at first cohabitation
\end{tabular}

\begin{tabular}{l} 
Age \\
\hline $15-19$ \\
\hline $20-24$ \\
Age at first cohabitation
\end{tabular}

\begin{tabular}{l} 
Age \\
\hline $15-19$ \\
\hline $20-24$ \\
Age at first cohabitation
\end{tabular}

$<18$

$>18$

Highest level education

\begin{tabular}{|c|c|c|c|}
\hline No education & $194[23]$ & $575[40]$ & 1 \\
\hline Primary & $439[52]$ & $719[49]$ & $1.41(1.06-1.86)^{*}$ \\
\hline Secondary & $148[18]$ & $127[9]$ & $2.42(1.60-3.65)^{*}$ \\
\hline Higher & $63[7]$ & $32[2]$ & $4.36(2.26-8.40)^{*}$ \\
\hline \multicolumn{4}{|l|}{ Religion } \\
\hline Orthodox & $477[56]$ & $410[28]$ & $6.86(4.67-10.08)^{*}$ \\
\hline Muslim & $148[18]$ & $722[50]$ & 1 \\
\hline Protestant & $201[24]$ & $265[18]$ & $5.56(3.53-8.77)^{*}$ \\
\hline Other & $18[2]$ & $55[4]$ & $4.48(1.73-11.61)^{*}$ \\
\hline \multicolumn{4}{|l|}{ Wealth index } \\
\hline Poorest & $94[11]$ & $387[27]$ & $0.35(0.22-0.56)^{*}$ \\
\hline Poorer & $193[23]$ & $369[25]$ & $0.93(0.61-1.41)$ \\
\hline Middle & $223[26]$ & $290[20]$ & $1.20(0.80-1.81)$ \\
\hline Richer & $177[21]$ & $223(15]$ & $1.12(0.75-1.69)$ \\
\hline Richest & $158[19]$ & $183[13]$ & 1 \\
\hline \multicolumn{4}{|c|}{ Number of living children } \\
\hline No children & $221[26]$ & $424[29]$ & 1 \\
\hline One -two & $578[68]$ & $846[58]$ & $1.12(1.55-2.68)^{*}$ \\
\hline Three and above & $47[6]$ & $183[13]$ & $2.30(0.54-1.44)$ \\
\hline \multicolumn{4}{|l|}{ Partners education } \\
\hline No education & $233[26]$ & $510[35]$ & 1 \\
\hline \multirow[t]{2}{*}{ Primary } & $362[43]$ & $670[46]$ & $1.18(0.88-1.57)$ \\
\hline & \multicolumn{2}{|c|}{ Page $15 / 37$} & \\
\hline
\end{tabular}

Modern contraceptive use (N, Crude odd ratio $\%)$

(COR)
Yes No

$187[22] \quad 401[27] \quad 1$

658[78] 1052[73] $1.11(0.39-1.46)$

$644[76] \quad 1171[81] \quad 1$

$201[24] \quad 282[19] \quad 0.89(0.66-1.18)$
No education

Primary

Higher

Religion

Orthodox

Muslim

Protestant

Other

Wealth index

Poorest 


\begin{tabular}{llll}
\hline Secondary & $156[19]$ & $206[14]$ & $1.30(0.88-1.92)^{*}$ \\
\hline Higher & $95[11]$ & $59[4]$ & $2.79(1.66-4.68)^{*}$ \\
\hline Don't know & $8[1]$ & $9[1]$ & $1.69(0.46-6.18)$
\end{tabular}

Respondent working status

\begin{tabular}{llll}
\hline No & $575[68]$ & $1171[80]$ & 1 \\
\hline Yes & $270[32]$ & $282[20]$ & $1.81(1.38-2.39)^{*}$ \\
\hline Partner occupation & & & \\
\hline No & $30[4]$ & $115[8]$ & 1 \\
\hline Services & $176[21]$ & $218[15]$ & $2.20(1.17-4.14)^{*}$ \\
\hline Agricultural & $451[53]$ & $904[62]$ & $1.62(0.90-2.94)^{*}$ \\
\hline Manual & $140[16]$ & $110[8]$ & $4.36(2.23-8.51)^{*}$ \\
\hline Other & $48[6]$ & $104[7]$ & $1.72(0.81-3.65)^{*}$ \\
\hline
\end{tabular}

Heard FP by mass media

\begin{tabular}{llll}
\hline No & $556[66]$ & $1126[78]$ & 1 \\
\hline Yes & $289[34]$ & $326[22]$ & $1.40(1.06-1.84)^{*}$ \\
\hline Heard FP community events & & & \\
\hline No & $503[60]$ & $956[66]$ & 1 \\
\hline Yes & $341[40]$ & $497[34]$ & $1.23(0.95-1.59)^{*}$ \\
\hline Field workers visit in last 12 month & & & \\
\hline No & $599[71]$ & $1071[74]$ & 1 \\
\hline Yes & $246[29]$ & $382[26]$ & $1.01(0.88-1.33)$
\end{tabular}

Health facility visit in last 12 month

\begin{tabular}{llll}
\hline No & $349[42]$ & $764[53]$ & 1 \\
\hline Yes & $496[58]$ & $691[47]$ & $1.53(1.21-1.94)^{*}$ \\
\hline Health facility distance & & & \\
\hline Big problem & $374[44]$ & $920[63]$ & $0.77(0.98-1.68)^{*}$ \\
\hline Not big problem & $471[56]$ & $533[37]$ & 1 \\
\hline Desire more children & & & 1 \\
\hline Have another & $736[87]$ & $1233[85]$ & $1.30(0.23-1.07)^{*}$ \\
\hline Undecided & $17[2]$ & $48[3]$ &
\end{tabular}


No more

\section{Husband desire more children}

\begin{tabular}{llll}
\hline Both want same & $430[51]$ & $575[40]$ & 1 \\
\hline Husband wants more & $132[15]$ & $317[22]$ & $0.46(0.33-0.64)^{*}$ \\
\hline Husband wants fewer & $49[6]$ & $68[5]$ & $0.88(0.51-1.50)$ \\
\hline Don't know & $234[28]$ & $492[33]$ & $0.63(0.47-0.83)^{*}$ \\
\hline $\begin{array}{l}\text { Decisions maker for } \\
\text { planning }\end{array}$ & family & & \\
\hline Mainly respondents & $163[19]$ & $239[16]$ & 1 \\
\hline Mainly husband & $39[5]$ & $122[8]$ & $0.47(0.27-0.82)^{*}$ \\
\hline Joint decisions & $642[76]$ & $718[49]$ & $1.53(1.12-2.10)^{*}$
\end{tabular}

*significant variable on bivariate analysis P-value less than 0.2

Table 4: Bi-variable multilevel logistic regression of modern contraceptive utilization and community level background characteristics in EDHS, 2016. 


\begin{tabular}{|c|c|c|c|c|}
\hline \multirow[t]{2}{*}{ Variable } & \multirow[t]{2}{*}{$\begin{array}{l}\text { Young married } \\
\text { women }(\mathrm{N}, \%)\end{array}$} & \multicolumn{2}{|c|}{$\begin{array}{l}\text { Modern contraceptive } \\
\text { use }(\mathrm{N}, \%)\end{array}$} & \multirow[t]{2}{*}{ Odd ratio } \\
\hline & & Yes & No & \\
\hline \multicolumn{5}{|l|}{ Place of residence } \\
\hline Urban & $321[14]$ & $191[23]$ & 129 [9] & 1 \\
\hline Rural & $1977[86]$ & $653[77]$ & $1323[91]$ & $\begin{array}{l}2.47(0.14- \\
0.40)^{*}\end{array}$ \\
\hline \multicolumn{5}{|l|}{ Community poverty level } \\
\hline low poverty & $1201[52]$ & $543[64]$ & $657[45]$ & 1 \\
\hline high poverty & $1097[48]$ & $302[36]$ & $796[55]$ & $\begin{array}{l}0.28(0.18- \\
0.44)^{*}\end{array}$ \\
\hline \multicolumn{5}{|l|}{$\begin{array}{l}\text { Community health services } \\
\text { utilization }\end{array}$} \\
\hline Low utilization & $1261[55]$ & $391[46]$ & $871[60]$ & 1 \\
\hline High utilization & $1037[45]$ & $454[54]$ & $582[40]$ & $\begin{array}{l}2.27(1.49- \\
3.46)^{*}\end{array}$ \\
\hline \multicolumn{5}{|l|}{$\begin{array}{l}\text { Community women } \\
\text { educational level }\end{array}$} \\
\hline Low $\quad$ educational level & 752 [33] & $150[18]$ & $602[41]$ & 1 \\
\hline High educational level & $1546[67]$ & $695[82]$ & $851[59]$ & $\begin{array}{l}\text { 6.47(4.03- } \\
10.40)^{*}\end{array}$ \\
\hline \multicolumn{5}{|l|}{$\begin{array}{l}\text { Community health facility } \\
\text { distance }\end{array}$} \\
\hline Big problem & $1467[64]$ & $409[48]$ & $1058[73]$ & $\begin{array}{l}3.51(2.10- \\
4.73)^{*}\end{array}$ \\
\hline Not big problem & $831[36]$ & $436[52]$ & 394 [27] & 1 \\
\hline \multicolumn{5}{|l|}{$\begin{array}{l}\text { Community mass media } \\
\text { exposure }\end{array}$} \\
\hline Low & $1928[84]$ & $632[75]$ & $1296[90]$ & 1 \\
\hline High & $369[16]$ & $213[25]$ & $157[10]$ & $\begin{array}{l}4.78(2.88- \\
7.95)^{*}\end{array}$ \\
\hline \multicolumn{5}{|l|}{ Region } \\
\hline Tigray & $192[8]$ & $76[9]$ & $115[8]$ & $\begin{array}{l}0.25(0.09- \\
0.68)^{*}\end{array}$ \\
\hline Afar & $35[2]$ & $5[1]$ & $30[2]$ & $\begin{array}{l}0.04(0.01- \\
0.18)^{*}\end{array}$ \\
\hline Amhara & $487[21]$ & $279[33]$ & $207[20]$ & $\begin{array}{l}0.84(0.33- \\
2.12)\end{array}$ \\
\hline Oromia & $968[42]$ & 249 [30] & $718[49]$ & $\begin{array}{l}0.13(0.05- \\
0.34)^{*}\end{array}$ \\
\hline Somali & $83[3]$ & $2[1]$ & $81[6]$ & $\begin{array}{l}0.02(0.01- \\
0.02)^{*}\end{array}$ \\
\hline Benishangul-Gumuz & $30[1]$ & $12[1]$ & $19[1]$ & $\begin{array}{l}0.22(0.06- \\
0.82)^{*}\end{array}$ \\
\hline SNNPR & $419[18]$ & $176[21]$ & $242[16]$ & $\begin{array}{l}0.27(0.10- \\
0.69) *\end{array}$ \\
\hline Gambela & $9[1]$ & $4[1]$ & $5[1]$ & $\begin{array}{l}0.25(0.03- \\
1.63) *\end{array}$ \\
\hline Harari & $7[1]$ & $2[1]$ & $5[1]$ & $\begin{array}{l}0.13(0.01- \\
1.14)^{*}\end{array}$ \\
\hline Addis Ababa & $55[2]$ & $35[4]$ & $20[1]$ & 1 \\
\hline Dire Dawa & $12[1]$ & $4[1]$ & $8[1]$ & $\begin{array}{l}0.17(0.03- \\
0.96)^{*}\end{array}$ \\
\hline
\end{tabular}

*significant variable on bivariate analysis P-value less than 0.2

Regional prevalence of modern contraceptive utilization 
The prevalence of modern contraceptive utilization among young married women varied across the regions of the country. The highest modern contraceptive utilization among young married women (63\%) was found in Addis Ababa region but lowestmodern contraceptive utilization (2\%) was in Somalia region (Figure 1).

\section{Spatial distribution of modern contraceptive utilization}

The analysis of spatial autocorrelation indicated that the spatial distribution of modern contraceptive utilizationamong young married women was non-random in the Ethiopia. The Global Moran's I values were 0.45 ( $p$ value $<0.0001$ ) that pointed out significant clustering of modern contraceptive utilizationamong young married women in the study area (Figure 2).

Gettis-OrdGi* analysis indicated high and low prevalence spot areas of modern contraceptive utilizationamong young married women. The highest prevalence spot areas for modern contraceptive utilization were detected in Addis Ababa, West and East Gojam. One the other hand, zone 1 of Afar region, Borena zone of Oromia region and all zone of Somalia regions werelowest prevalence spot area (Figure 3).

Spatial scan statistics identified significant primary ( $L L R=113.3, P<0.001)$ and secondary $(L L R=19.1$, $\mathrm{P}<0.001$ ) clusters of modern contraceptive utilizationamong young married women (Table 5). The large primary clusters spatial window encompasses inall zone of Amhara region, East Shewa, South andWestShewa, SouthShewa, East and H.G. Wellega and North Shewa zone of Oromia region, Metekel and kinashi zone of Benishangual, Addis Ababa.It was centered at $10.575333 \mathrm{~N}, 37.480816 \mathrm{E}$ with $293.86 \mathrm{~km}$ with a relative risk (RR) of 2.28. Relatively small secondary clusters located in spatial window which encompass in Sheka, Sidamo, keff and northern BenchiMaji zone. It was centered at $6.856667 \mathrm{~N}$, $38.360928 \mathrm{E}$ with $30.97 \mathrm{~km}$ a relative risk (RR) of 2.15 (Figure 4).

e 5: List of modern contraceptive utilization that significant cluster for Ethiopia in EDHS 16.

\begin{tabular}{llllllll}
\hline Type of cluster & \#population & $\begin{array}{l}\# \\
\text { case }\end{array}$ & RR & $\begin{array}{l}\text { Case in } \\
\text { area }\end{array}$ & LLR & $\begin{array}{l}\text { Radius } \\
\mathrm{km}\end{array}$ & P-value \\
\hline $\begin{array}{l}\text { Most likely } \\
\text { cluster }\end{array}$ & 699 & 417 & 2.28 & 59.7 & 113.3 & 293.86 & $0.00001^{* *}$ \\
\hline $\begin{array}{l}\text { Secondary } \\
\text { cluster }\end{array}$ & 56 & 43 & 2.15 & 76.8 & 19.3 & 30.97 & $0.001^{*}$ \\
\hline
\end{tabular}

LLR=likelihood ratios $* * \mathrm{P}<0.001 * * \mathrm{P}<0.0001 \quad \mathrm{RR}=$ relative risk

\section{Factor associated with modern contraceptive utilization}

\section{Bi-variable multilevel logistic regression}


Individual and community level variable computed using Bi-variable multilevel logistics analysis.All variable $p$ value up to 0.2 was selected to fit multi-variable multilevel logistics model. Educational level, wealth index, religious, number of living children, place of residence, region, respondent working status,partner occupation, , mass media exposure about family planning, health facility visit within 12 month, desire more children, husband desire more children, partner education, perception of distance from health facility, community discussion about family planning, community level of poverty, community health services utilization, and community health facility accessibility pass bi-variable multilevel logistics regression analysis. But age of respondent, age of cohabitation, and field worker visits in 12 months were not pass bi-variable multilevel logistic regression analysis $p$ value less than 0.2 (Table 3 and 4).

\section{Multi-variable multilevel logistic regression}

Multilevel logisticregression analyses include both individual and community-level factors of modern contraceptive utilization in four models. Model four were selected that fitted for both individual and community level factor based on Log-likelihood ratio(Table 6 and 7).Finally, multivariable logistic regression of model four indicated that religion, number of living children, husband desire more children, respondent working status, region, and community exposure to mass mediaand community educational level were statically significant variables for modern contraceptive utilizationin this study (Table 6).

le 6: Adjusted multilevel logistic regression result of both individual and community level ors associated with modern contraceptive utilization among married women in EDHS 2016. 


\begin{tabular}{|c|c|c|c|c|}
\hline \multirow[t]{2}{*}{ Characters } & \multirow{2}{*}{$\begin{array}{l}\text { Model } \\
\text { one }\end{array}$} & Model two & Model three & Model four \\
\hline & & AOR (95\%CI) & AOR $(95 \% \mathrm{CI})$ & AOR (95\%CI) \\
\hline \multicolumn{5}{|l|}{ Religious } \\
\hline Orthodox & & $\begin{array}{l}5.33(3.55- \\
8.00)^{* * *}\end{array}$ & & $3.19(2.05-4.96)^{* * *}$ \\
\hline Muslim & & 1 & & 1 \\
\hline Protestant & & $\begin{array}{l}4.41(2.72- \\
7.14)^{* * *}\end{array}$ & & $3.77(2.21-6.40)^{* * *}$ \\
\hline Other & & $\begin{array}{l}3.96(1.42- \\
11.01)^{* *}\end{array}$ & & $3.15(1.12-8.89)^{*}$ \\
\hline \multicolumn{5}{|l|}{$\begin{array}{l}\text { Women } \\
\text { Education }\end{array}$} \\
\hline No education & & 1 & & 1 \\
\hline Primary & & $\begin{array}{l}1.30(0.94- \\
1.78)\end{array}$ & & $1.02(0.73-1.43)$ \\
\hline Secondary & & $\begin{array}{l}1.96(1.20- \\
3.19)^{*}\end{array}$ & & $1.52(0.91-2.53)$ \\
\hline Higher & & $\begin{array}{l}2.71(1.18- \\
6.21)^{* *}\end{array}$ & & $1.71(0.73-3.99)$ \\
\hline
\end{tabular}

Wealth index

\begin{tabular}{|c|c|c|}
\hline Poorest & $\begin{array}{l}0.55(0.33- \\
0.92)^{*}\end{array}$ & $0.71(0.41-1.24)$ \\
\hline Poorer & $\begin{array}{l}1.25(0.79- \\
1.94)\end{array}$ & $1.24(0.77-2.00)$ \\
\hline Middle & $\begin{array}{l}1.51(0.98- \\
2.33)\end{array}$ & $1.45(0.10-2.27)$ \\
\hline Richer & $\begin{array}{l}1.33(0.86- \\
2.05)\end{array}$ & $1.25(0.81-1.94)$ \\
\hline Richest & 1 & 1 \\
\hline \multicolumn{3}{|c|}{ Women working status } \\
\hline No & 1 & 1 \\
\hline Yes & $\begin{array}{l}1.52(1.13- \\
2.03)\end{array}$ & $1.47(1.10-1.98)^{*}$ \\
\hline
\end{tabular}

Partners education

No education

Primary

1

0.94(0.68-
1

0.92(0.66-1.27) 


\begin{tabular}{|c|c|c|}
\hline Secondary & $\begin{array}{l}0.82(0.52- \\
1.27)\end{array}$ & $0.73(0.46-1.14)$ \\
\hline Higher & $\begin{array}{l}1.27(0.65- \\
2.47)\end{array}$ & $1.12(0.56-2.20)$ \\
\hline Don't & $\begin{array}{l}2.56(0.61- \\
10.72)\end{array}$ & $1.92(0.44-8.29)$ \\
\hline \multicolumn{3}{|l|}{$\begin{array}{l}\text { Partner } \\
\text { occupation }\end{array}$} \\
\hline No & 1 & 1 \\
\hline Professional & $\begin{array}{l}1.37(0.69- \\
2.71)\end{array}$ & $1.20(0.60-2.42)$ \\
\hline Agriculture & $\begin{array}{l}1.42(0.76- \\
2.64)\end{array}$ & $1.23(0.65-2.32)$ \\
\hline Manual & $\begin{array}{l}2.54(1.24- \\
5.16)^{*}\end{array}$ & $2.33(0.99-4.30)$ \\
\hline Other & $\begin{array}{l}1.14(0.50- \\
2.57)\end{array}$ & $0.94(0.41-2.16)$ \\
\hline \multicolumn{3}{|c|}{ Number of living children } \\
\hline No child & 1 & 1 \\
\hline One -two child & $\begin{array}{l}2.57(1.89- \\
3.49) * * *\end{array}$ & $2.69(1.98-3.66)^{* * *}$ \\
\hline Three and above & $\begin{array}{l}1.51(0.87- \\
2.60)\end{array}$ & $1.61(0.09-2.80)$ \\
\hline \multicolumn{3}{|c|}{ Exposure to mass media about FP } \\
\hline No & 1 & 1 \\
\hline Yes & $\begin{array}{l}0.99(0.72- \\
1.37)\end{array}$ & $0.88(0.63-1.24)$ \\
\hline \multicolumn{3}{|c|}{ Visit health facility in last 12 month } \\
\hline No & 1 & 1 \\
\hline Yes & $\begin{array}{l}1.26(0.97- \\
1.63)\end{array}$ & $1.26(0.95-1.66)$ \\
\hline
\end{tabular}

Community discussion about family planning

\begin{tabular}{lll}
\hline No & 1 & 1 \\
\hline Yes & $\mathbf{0 . 9 4 ( 0 . 6 4 -}^{*}$ & $0.91(0.69-1.21)$ \\
& $\mathbf{0 . 7 1}^{*}$ &
\end{tabular}

Distance from health facility 
Big problem

0.94(0.70-

$1.21(0.88-1.68)$

1.24)

No big problem

1

1

Fertility

preferences

\begin{tabular}{lll}
\hline Have another & 1 & 1 \\
\hline Undecided & $0.50(0.22-$ & $0.50(0.22-1.13)$ \\
& $1.14)$ & \\
\hline No more & $0.79(0.52-$ & $0.69(0.46-1.03)$ \\
& $1.18)$ & \\
\hline Husband's desire for children & & \\
\hline Both want same & 1 & 1 \\
\hline Husband want & $\mathbf{0 . 5 2 ( 0 . 3 6 -}$ & $\mathbf{0 . 5 5 ( 0 . 3 9 - 0 . 7 9 ) ^ { * * * }}$ \\
more & $\mathbf{0 . 7 3 ) * * *}$ & $0.96(0.55-1.70)$ \\
\hline Husband want & $0.97(0.55-$ & $\mathbf{0 . 6 9 ( 0 . 5 1 - 0 . 9 3 ) *}$ \\
fewer & $1.70)$ & \\
\hline Don't & $0.76(0.56-$ & \\
& $1.01)$ & \\
\hline
\end{tabular}

\begin{tabular}{|c|c|c|}
\hline $\begin{array}{l}\text { Place } \\
\text { residence }\end{array}$ & & \\
\hline Urban & 1 & 1 \\
\hline Rural & $\begin{array}{l}0.56(0.28- \\
1.08)^{* *}\end{array}$ & $0.78(0.37-1.64)$ \\
\hline \multicolumn{3}{|l|}{ Region } \\
\hline Tigre & $\begin{array}{l}1.09(0.39- \\
3.00)\end{array}$ & $0.75(0.26-2.18)$ \\
\hline Afar & $\begin{array}{l}0.36(0.07- \\
1.64)\end{array}$ & $0.80(0.15-4.21)$ \\
\hline Amhara & $\begin{array}{l}4.63(1.70- \\
12.59) * *\end{array}$ & $5.00(1.74-14.32)^{* *}$ \\
\hline Oromia & $\begin{array}{l}0.70(0.26- \\
1.87)\end{array}$ & $0.95(0.34-2.64)$ \\
\hline Somali & $\begin{array}{l}0.03(0.01- \\
0.27)^{* *}\end{array}$ & $0.07(0.01-0.63)^{*}$ \\
\hline $\begin{array}{l}\text { Benishangul- } \\
\text { Gumuz }\end{array}$ & $\begin{array}{l}1.03(0.27- \\
3.87)\end{array}$ & $1.05(0.27-4.16)$ \\
\hline SNNPR & $\begin{array}{l}1.41(0.52- \\
3.79)\end{array}$ & $1.02(0.35-2.95)$ \\
\hline
\end{tabular}


Gambela
$0.92(0.14-$
$0.68(0.10-4.70)$

\section{$5.78)$}

Harari

$0.34(0.04-$

2.89)

0.69(0.07-6.49)

$\mathbf{0 . 5 5 ( 0 . 0 9 - 0 . 3 ) * 1 . 2 1 ( 0 . 2 0 - 7 . 4 6 )}$

Dire 1

AdisAbeba

Community health service utilization

\begin{tabular}{|c|c|c|}
\hline Low & 1 & 1 \\
\hline High & $\begin{array}{l}1.17[0.78- \\
1.75]\end{array}$ & $1.01(0.65-1.57)$ \\
\hline \multicolumn{3}{|l|}{ Community access to health services } \\
\hline Big problem & 1 & 1 \\
\hline No big problem & $\begin{array}{l}1.22[0.77- \\
1.91]\end{array}$ & $1.40(0.84-2.33)$ \\
\hline \multicolumn{3}{|l|}{ Community poverty level } \\
\hline Low poverty & 1 & 1 \\
\hline High poverty & $\begin{array}{l}0.62[0.41- \\
0.92]^{*}\end{array}$ & $0.78(0.49-1.25)$ \\
\hline \multicolumn{3}{|l|}{ Community mass media exposure } \\
\hline Low & 1 & 1 \\
\hline High & $\begin{array}{l}1.95[1.09- \\
3.47]^{*}\end{array}$ & $1.94(1.03-3.65)^{*}$ \\
\hline \multicolumn{3}{|l|}{ Community education level } \\
\hline Low & 1 & 1 \\
\hline High & $\begin{array}{l}3.04[1.88- \\
4.91]^{* * *}\end{array}$ & $2.88(1.69-4.91)^{* * *}$ \\
\hline
\end{tabular}

Model one: empty model no variable. CI: Confidence interval, AOR: adjusted odds ratio, 1: Reference category $* \mathrm{P}<0.05 ;{ }^{* *} \mathrm{P}<0.01 ;{ }^{* * *} \mathrm{P}<0.001$

Individual level factor:Religious of young women influence the utilization of contraceptive those Orthodox and Protestant followers were 3.19 time (AOR=3.19; Cl: 2.05-4.96) and 3.77 time (AOR=3.77; Cl: 2.216.40) more likely to use modern contraceptive than Muslimfollower. Young married women who has work were1.52 times (AOR=1.52; $\mathrm{Cl}$ : 1.13-2.03)more likely to use modern contraceptive. Husband's desire for children affect contraceptive use those young women whose husband want more children were $49 \%$ (AOR $=0.55 ; \mathrm{Cl}:(0.39-0.79)$ less likely to use modern contraceptive. Those young married women who have one or two children were2.69time (AOR=2.69; $95 \% \mathrm{Cl}$ : 1.98-3.66) morelikely to use modern contraceptive. 
Community level factor: Young married women in Amhara region 5 time (AOR=5.00; 95\% Cl: 1.74-14.32) more likely to use modern contraceptive, but Somalia region $99.83 \%(\mathrm{AOR}=0.07 ; 95 \% \mathrm{Cl}$ : 0.01-0.63) less likely to use modern contraceptive. Those young married women who were exposed to mass mediawere1.94 times (AOR=1.94; 95\% Cl: 1.03-3.65)more likely to use modern contraceptive. In addition, young married women who lived in high educated community were 2.88 times ( $\mathrm{AOR}=2.88$; $\mathrm{Cl}$ : 1.69-4.91) more likely to use modern contraceptive.

Regarding to ICC, in empty model $46 \%$ of the total variance was accounted by between-cluster variation of modern contraceptive utilization among young married women (ICC=0.46, $\sigma=.036$ ). This calculated ICC (0.46) value informs us to use multilevel logistic regression over the basic regression model. Similarly, ICC in successive model indicate $38 \%, 33 \%$ and $34 \%$ of the variation among the clusters was attributed to individual level factor, community level factors, and both individual and community level factors respectively.

Community level factor showed up with higher PCV, $43 \%$ variance of modern contraceptive utilization among young married womenexplained by community levels factor. Additionally $20 \%$ and $42 \%$ variance of modern contraceptive utilization among young married women explained by individual level factor, and both individual and community level factors respectively (Table 7).

Table 7: Measure of variations and model fitness

\begin{tabular}{|l|l|l|l|l|l|}
\hline Characters & & Model one & Model two & Model three & Model four \\
\hline Random effect & Variance & 2.77 & 2.02 & 1.58 & 1.6 \\
\hline Measure of variation & ICC & 46 & 38 & 32 & 33 \\
\hline & PCV & Reference & 27 & 43 & 42 \\
\hline Model diagnostics & Log-likelihood & -1284 & -1160 & -1189 & $-1111^{*}$ \\
\hline & DIC & 2568 & 2320 & 2378 & $2222^{*}$ \\
\hline & AIC & 2573 & 2384 & 2414.2 & $2318.9^{*}$ \\
\hline
\end{tabular}

$\mathrm{PCV}=$ Proportional change in variance, AIC=Akaike information criterion $*$ Fitted statistics.

\section{Multicollinarity}

Multicollinearity amongst the individual and communitylevel variables associated with modern contraceptive use was checked using the Variance Inflation Factor (VIF). In the current study, the mean VIF value was estimated to be 1.98 , minimum value 1.06 and maximum value 5.49 .

\section{Discussion}

Increase modern contraceptive utilization among young married women has a major role of improving health by decrease unwanted pregnancy particularly for developing country. To increase utilization of modern contraceptive among young married women, knowing its geographical variation and associated factor will bring considerable effect in future improvement of family planning program that focus on younger population group. 
In this study modern contraceptive utilization among young married women in this study was $36.7 \%$ [95 $\%$ Cl: $34.8 \%, 38.7 \%]$. It was similar with study done in Uganda(7),and the possible reason may be similar emphasizing given by the local health programmers. Itwas higher than study done in Malawi(38).But it waslowwhen compared to study done in Bangladesh(39), Ghana (5). This variation might be due to the involvement of health extension workers in family planning awareness creation activity, difference in provision of health service encompass quality family planning serviceincluding in school through different club related to reproductive health programmers, availability of youth friendly health service or difference of study population (40-42).

The spatial distribution of modern contraceptive among young married women across Ethiopia region showed significant variation and clustering at zonal level. The Global Moran's I values 0.42 ( $p$ value $<0.001$ ) indicated spatial heterogeneity modern contraceptive among young married that need to identify gaps and to prioritize intervention (21).Gettis-OrdGi* statistics indicate highest prevalence zone for modern contraceptive utilization were detected in Addis Ababa, West and East Gojam. One the other hand zone 1 of Afar region, Borena zone of Oromia region and all zone of Somalia regions were lowest prevalence area zone (Figure). It was consistence with study done in Kenya and India which indicate modern contraceptive utilization across districts were significant variation and clustering $(43,44)$.

Spatial scan statistics identified primary cluster $(L L R=113.3, P<0.001)$ encompass all zone of Amhara region, East Shewa, South and West Shewa, South Shewa, East and H.G. Wellega and North Shewa zone of Oromia region, Metekel and kinashi zone of Benishangual has 2.28 times more likely to use modern contraceptive utilization than married women outside these zone $(\mathrm{RR}=2.28)$. Additionally secondary cluster (LLR= 19.1, P<0.001) encompass in Sheka, Sidamo, keff and northern BenchiMaji zone has 2.15 times more likely to use modern contraceptive utilization than married women outside these zone. Geographical variation and clustering of modern contraceptive utilization reported by similar study done Rwanda and Ethiopia $(45,46)$. These s studies explain geography, culturalfactors, demographic characteristics of respondents, health service delivery capacity and community awareness about FP is possible explanation for regional variations of modern contraceptive utilization(43-46)

The multilevel analysis shows that there is a big variation in use of modern contraceptiveamong young married women at both at the individual and community level variable. In this study religion,respondent working status, husband desire more children, number of living children, region, community mass media exposure and community educational level were statically significant variables for modern contraceptive utilizationamong young married women (Table 7).

Religious of respondent were significantly associated with modern contraceptive utilizationamong young married women. Christiansand other religious followers were more likely to use modern contraceptive than Muslim. This finding had agreement with study done in Malawi(38), Ethiopia(46) and Bangladesh (47). The possible explanation might be religion is critical sociocultural dimensions that had significant impacts on attitudes towards and the uptake of modern contraceptive methods utilization (48). 
Number of living children positivity associated with modern contraceptive utilizationamong young married women. If women have more birth they would bemore likely they have modern contraceptive utilizationamong young married women. Study revealed in Ethiopia(49)and Rwanda (45)indicates a number of children was found to be a positively associated determinant for amodern contraceptive utilization. This result would indicate the likelihood of desire no more children increases with the actual number of living children (50).

Women working status in this study associated factor with women's modern contraceptive utilizationamong young married women. Study showed that women who had work were more likely to use modern contraceptive than who had not which supported by study done in Rwanda (45)and Malawi(38).

Husband desire more children where associated with modern contraceptive utilizationthose young women whose husband want more children were less likely to use modern contraceptive. This has agreement with study done in Egypt (46) and Ghana (51). The possible explanation might be those decide desire number of children is tendency to access family planning services (52). Women's internal motivations to achieve their child spacing goal could be the possible reason for higher level of modern contraceptive utilizationamong young married women.

This study also revealed geographical region where a woman lived was found to be an important predictor of modern contraceptive utilization. This supported by study done in Malawi(38), Bangladesh(39) and Uganda(7). This might be due to the fact that attributable to the tendency of some region to have higher fertility compared to others. Additional reason might be availability of quality of family planning services, cultural and religious reason (53).

Community exposure to mass media increases the utilization modern contraceptive among young married women. It is support by study done inUganda(7) Angola(54) andEthiopa(55). For young people media is top source of information use excessive including Television, radio, and newspapers. Mass media widely used whicheasily reach a large proportion of population and credible sources of information that have capacity to raise awareness, increase knowledge level, and influence attitudes towards family planning (56).

Community educational level found to have a positive significant association with modern contraceptive utilization. Young married women who lived in high educated community were more likely to use modern contraceptive. Likewise, this is support by study done in low and middle-income countries and Zimbabwe $(17,18)$. The possible explanation might be increasing education might help the discussion on contraceptive and would increase knowledge and utilization of FP methods. Education improves cognitive skills, awareness about health, financial resources and decision-making power. It provides improved access to the mass media, knowledge and attitude about family planning, access to contraception, correct use of contraception, and finally promotes contraceptive use(57).

\section{LIMITATION OF STUDY}

Page 27/37 
Including Geographical Positioning System can contribute to show more information about modern contraceptive utilization but all cluster has no GPS which few cluster is excluded from this study. This would limit to show modern contraceptive utilization among young married women in some area of country. This study not include modern contraceptive utilization among unmarried young woman those who are sexually active which need further research to encompass all issue of modern contraceptive utilization. Moreover, this research has limitation to dig out why women not use modern contraceptive that needs qualitative study in low prevalence spot area of modern contraceptive utilizationamong young married women.

\section{Conclusion}

Over all modern contraceptive utilization among young married women age between 15-24 years in Ethiopia was $36.7 \%$. This study showed that there was a low prevalence of modern contraceptive utilization among young married women age between 15-24 years in the Ethiopia. Religion ,respondent working status, husband desire more children, region, community exposure to mass mediaand community educational level were statically significant variables for modern contraceptive utilization.

Modern contraceptive utilization is a valuable indicator for national family planning programs especially for those young women because it shows how well achieving a key issue of family planning. Intervention to increase modern contraceptive utilization should be by considering geographical variation and factor associated with it. Determinant ofmodern contraceptive utilization is not only individual characteristics of the young married women but also community-level factors that associated with it. Thus efforts to increase modern contraceptive utilization among young married women age between 15-24 years in Ethiopia should focus both on individuals and on communities.

\section{List Of Abbreviations}

LLR: Log Likelihood Ratio; FP: family planning; SNNP: Southern Nations, Nationalities and Peoples;GPS: Global Positioning System; DHS: Demographic and Health Survey, EDHS: Ethiopian Demographic and Health Survey, RR: Relative Risk

\section{Declarations}

\section{Ethics approval and consent to participate}

Ethical clearance was obtained from the ethical review board of Ethiopia public health association $(E P H I)$.Written consent to use family planning data was obtained from Measure DHS International Program which authorized the data-sets and GPS coordinate files. All of the data that used for analysis of modern contraceptive utilizationwere availablepublicly. Data downloaded from DHS website treated as confidential, and no effort was taken to identify any of household or individual respondent interviewed in EDHS survey that was maintained through identification number rather than names. 


\section{Consent to Publication}

Not applicable

\section{Availability of data and materials}

Family planning and GPSdataset is available from measure DHS program website. All relevant data about modern contraceptive utilization are included in the manuscript. However, the minimal data underlying all the findings about modern contraceptive utilizationin the manuscript will be available upon request.

\section{Competing interest}

The authors declare that they have no competing interestin this study area.

\section{Funding}

No funding

\section{Authors' contributions}

K.A.; acquired the data from DHS website, manage and analyzed the data for this study, interpreted the results and drafted the manuscript. A.M and E.T; they contributed in the conceptualization and design of the study, and review the manuscript critically. All authors involved in review and approval of the final manuscript submitted.

\section{Acknowledgments}

We are grateful to DHS measures for allowing us to use family planning dataset for further analysis. We also grateful Ethiopian Central Statistical Agency (CSA) for providing census tract shaped files of Ethiopia. We thank Dessie health Science College and Ethiopia public health association (EPHI) for helping us in research process.

\section{Authors Information}

${ }^{1}$ Department of Health informatics, Dessie Health Science College, Ethiopia

${ }^{2}$ Department of nursing, Dessie Health Science College, Ethiopia

\section{References}

1. Federal Democratic Republic of Ethiopia:Ministry of Health :Basics in Family Planning \& Short Acting Family Planning. 2012.

2. U.S. Agency for International ,Development Family planning in Ethiopia November 2012. 
3. Darroch JE, Woog V, Bankole A, Ashford LS, Points K. Costs and benefits of meeting the contraceptive needs of adolescents. Guttmacher Institute. 2016.

4. Tsui AO, Brown W, Li Q. Contraceptive practice in sub-Saharan Africa. Population and development review. 2017;43(Suppl Suppl 1):166.

5. Grindlay K, Dako-Gyeke P, Ngo TD, Eva G, Gobah L, Reiger ST, et al. Contraceptive use and unintended pregnancy among young women and men in Accra, Ghana. PloS one. 2018;13(8).

6. Denno DM, Hoopes AJ, Chandra-Mouli V. Effective strategies to provide adolescent sexual and reproductive health services and to increase demand and community support. Journal of adolescent health. 2015;56(1):S22-S41.

7. Asiimwe JB, Ndugga P, Mushomi J, Ntozi JPM. Factors associated with modern contraceptive use among young and older women in Uganda; a comparative analysis. BMC public health. 2014;14(1):926.

8. Krugu JK, Mevissen F, Münkel M, Ruiter R. Beyond love: a qualitative analysis of factors associated with teenage pregnancy among young women with pregnancy experience in Bolgatanga, Ghana. Culture, health \& sexuality. 2017;19(3):293-307.

9. Patton GC, Sawyer SM, Santelli JS, Ross DA, Afifi R, Allen NB, et al. Our future: a Lancet commission on adolescent health and wellbeing. The Lancet. 2016;387(10036):2423-78.

10. Loaiza E, Liang M. Adolescent pregnancy. A Review of the Evidence UNFPA New York: UNFPA. 2013:8-10.

11. Jain A, Ismail H, Tobey E, Erulkar A. Stigma as a barrier to family planning use among married youth in Ethiopia. Journal of biosocial science. 2019;51(4):505-19.

12. Ochako R, Mbondo M, Aloo S, Kaimenyi S, Thompson R, Temmerman M, et al. Barriers to modern contraceptive methods uptake among young women in Kenya: a qualitative study. BMC public health. 2015;15(1):118.

13. Subramanian L, Simon C, Daniel EE. Increasing contraceptive use among young married couples in Bihar, India: evidence from a decade of implementation of the PRACHAR project. Global Health: Science and Practice. 2018;6(2):330-44.

14. Ewerling F, Victora CG, Raj A, Coll CV, Hellwig F, Barros AJ. Demand for family planning satisfied with modern methods among sexually active women in low-and middle-income countries: who is lagging behind? Reproductive health. 2018;15(1):42.

15. Worku AG, Tessema GA, Zeleke AA. Trends of modern contraceptive use among young married women based on the 2000,2005 , and 2011 ethiopian demographic and health surveys: A multivariate decomposition analysis. PloS one. 2015;10(1):e0116525.

16. Morris JL, Rushwan H. Adolescent sexual and reproductive health: The global challenges. International Journal of Gynecology \& Obstetrics. 2015;131:S40-S2.

17. Remez L, Woog V, Mhloyi M. Sexual and Reproductive Health Needs of Adolescents in Zimbabwe. Issues in Brief (Alan Guttmacher Institute). 2014(3):1-8. 
18. Mutumba M, Wekesa E, Stephenson R. Community influences on modern contraceptive use among young women in low and middle-income countries: a cross-sectional multi-country analysis. BMC Public Health. 2018;18(1):430.

19. Starbird E, Norton M, Marcus R. Investing in family planning: key to achieving the sustainable development goals. Global health: science and practice. 2016;4(2):191-210.

20. Organization WH. Summary report on the WHO/UNAIDS/UNFPA/UNICEF joint regional meeting on the Global Accelerated Action for the Health of Adolescents: Guidance to Support Country Implementation, Cairo, Egypt, 20-21 March 2017. World Health Organization. Regional Office for the Eastern Mediterranean; 2017.

21. Cartwright AF, Otai J, Maytan-Joneydi A, McGuire C, Sullivan E, Olumide A, et al. Access to family planning for youth: perspectives of young family planning leaders from 40 countries. Gates Open Research. 2019;3(1513):1513.

22. Radovich E, Dennis ML, Wong KL, Ali M, Lynch CA, Cleland J, et al. Who meets the contraceptive needs of young women in sub-Saharan Africa? Journal of Adolescent Health. 2018;62(3):273-80.

23. Brittain AW, Briceno ACL, Pazol K, Zapata LB, Decker E, Rollison JM, et al. Youth-friendly family planning services for young people: a systematic review update. American journal of preventive medicine. 2018:55(5):725-35.

24. Mazur A, Brindis CD, Decker MJ. Assessing youth-friendly sexual and reproductive health services: a systematic review. BMC health services research. 2018;18(1):216.

25. Zuurmond MA, Geary RS, Ross DA. The effectiveness of youth centers in increasing use of sexual and reproductive health services: a systematic review. Studies in family planning. 2012;43(4):239-54.

26. CSA. Ethiopia demographic and health survey 2016: Key Indicators Report . October 2016

27. Federal Democratic Republic of Ethiopia Ministry of Health:Annual performance report ,. October 9 , 2018.

28. Federal Democratic Republic of Ethiopia Ministry of Health:Health sector transformation plan 2015/16 - 2019/20(2008-2012 EFY). August 2015.

29. Abate MG, Tareke AA. Individual and community level associates of contraceptive use in Ethiopia: a multilevel mixed effects analysis. Archives of Public Health. 2019;77(1):46.

30. Zimmerman LA, Bell SO, Li Q, Morzenti A, Anglewicz P, Group PPI, et al. Individual, community and service environment factors associated with modern contraceptive use in five sub-Saharan African countries: a multilevel, multinomial analysis using geographically linked data from PMA2020. PloS one. 2019;14(6):e0218157.

31. Dirk U. Pfeiffer TPR, Mark Stevenson,Kim B. Stevens ,David J. Rogers and Archie C. A. Clements Spatial Analysis in Epidemiology. 2008.

32. Chainey S. Advanced hotspot analysis: spatial significance mapping using Gi*. UCL Jill Dando Institute of Crime Science, University College London, London. 2010. 
33. Grubesic TH, Murray AT, editors. Detecting hot spots using cluster analysis and GIS. Proceedings from the fifth annual international crime mapping research conference; 2001.

34. Kulldorff M. SaTScanTM User Guide:. March, 2018.

35. Austin PC. Estimating multilevel logistic regression models when the number of clusters is low: a comparison of different statistical software procedures. The international journal of biostatistics. 2010;6(1):Article 16.

36. Snijders TAB. Multilevel analysis :An Introduction to Basic and Applied Multilevel Analysis. 2012.

37. Bardenheier BH, Shefer A, Barker L, Winston CA, Sionean CK. Public health application comparing multilevel analysis with logistic regression: immunization coverage among long-term care facility residents. Annals of epidemiology. 2005;15(10):749-55.

38. Mandiwa C, Namondwe B, Makwinja A, Zamawe C. Factors associated with contraceptive use among young women in Malawi: analysis of the 2015-16 Malawi demographic and health survey data. Contraception and reproductive medicine. 2018;3(1):1-8.

39. Islam AZ. Factors affecting modern contraceptive use among fecund young women in Bangladesh: does couples' joint participation in household decision making matter? Reproductive health. 2018;15(1):112.

40. Mekonnen W, Worku A. Determinants of low family planning use and high unmet need in Butajira District, South Central Ethiopia. Reproductive Health. 2011;8(1):37.

41. Deus O. BARRIERS TO UPTAKE OF FAMILY PLANNING SERVICES AMONG WOMEN OF REPRODUCTIVE AGE (18-45 YEARS) IN MFANGANO ISLAND, HOMABAY COUNTY, KENYA: Pwani University; 2017.

42. Sedgh G, Hussain R. Reasons for contraceptive nonuse among women having unmet need for contraception in developing countries. Studies in family planning. 2014;45(2):151-69.

43. New JR, Cahill N, Stover J, Gupta YP, Alkema L. Levels and trends in contraceptive prevalence, unmet need, and demand for family planning for 29 states and union territories in India: a modelling study using the Family Planning Estimation Tool. Lancet Glob Health. 2017;5(3):e350-e8.

44. Ettarh RR. Spatial analysis of contraceptive use and unmet need in Kenya. 2011.

45. Habyarimana F, Ramroop S. Spatial Analysis of Socio-Economic and Demographic Factors Associated with Contraceptive Use among Women of Childbearing Age in Rwanda. International journal of environmental research and public health. 2018;15(11):2383.

46. El-Moselhy EA, Moftah FM, Darwish MM, Abo-Rahma AH. Trends and Determinants of Contraceptive Use among Young (15-24 Year) Married Women: A Secondary Analysis Based on the 2008 and 2014 Egypt Demographic and Health Surveys. Egyptian Journal of Hospital Medicine. 2017;66.

47. Tamang L, Raynes-Greenow C, McGeechan K, Black K. Factors associated with contraceptive use among sexually active Nepalese youths in the Kathmandu Valley. Contraception and reproductive medicine. 2017;2(1):13. 
48. Abdulla S. Religious Affiliation and contraceptive use in Kenya: University of the Witwatersrand, Faculty of Humanities, School of Social ...; 2014.

49. Mohammed A, Woldeyohannes D, Feleke A, Megabiaw B. Determinants of modern contraceptive utilization among married women of reproductive age group in North Shoa Zone, Amhara Region, Ethiopia. Reproductive health. 2014;11(1):13.

50. Wulifan JK, Brenner S, Jahn A, De Allegri M. A scoping review on determinants of unmet need for family planning among women of reproductive age in low and middle income countries. BMC women's health. 2015;16(1):2.

51. Aviisah PA, Dery S, Atsu BK, Yawson A, Alotaibi RM, Rezk HR, et al. Modern contraceptive use among women of reproductive age in Ghana: analysis of the 2003-2014 Ghana Demographic and Health Surveys. BMC Womens Health. 2018;18(1):141.

52. Wilopo SA, Setyawan A, Pinandari AW, Prihyugiarto T, Juliaan F, Magnani RJ. Levels, trends and correlates of unmet need for family planning among postpartum women in Indonesia: 2007-2015. BMC Womens Health. 2017;17(1):120.

53. Sah S, Jaiswal A, Paul P. CURRENT STATUS OF CONTRACEPTIVES USE. 2018.

54. Prata N, Bell S, Weidert K, Nieto-Andrade B, Carvalho A, Neves I. Varying family planning strategies across age categories: differences in factors associated with current modern contraceptive use among youth and adult women in Luanda, Angola. Open access journal of contraception. 2016;7:1.

55. Jembere Gizachew Balew YC, Clara Tammy Kim, and Woorim Ko. Structural Determinants in Family Planning Service Utilization in Ethiopia: EDHS 2011 Analysis. BioMed research international. November 2015:17 pages.

56. Ajaero CK, Odimegwu C, Ajaero ID, Nwachukwu CA. Access to mass media messages, and use of family planning in Nigeria: a spatio-demographic analysis from the 2013 DHS. BMC public health. 2016;16:427.

57. Ahmed A, Zahangir MS. The Impact of Education and Residence on Current Use of Contraception in Ethiopian Women. Global Journal of Health Science. 2019;11(9).

\section{Figures}




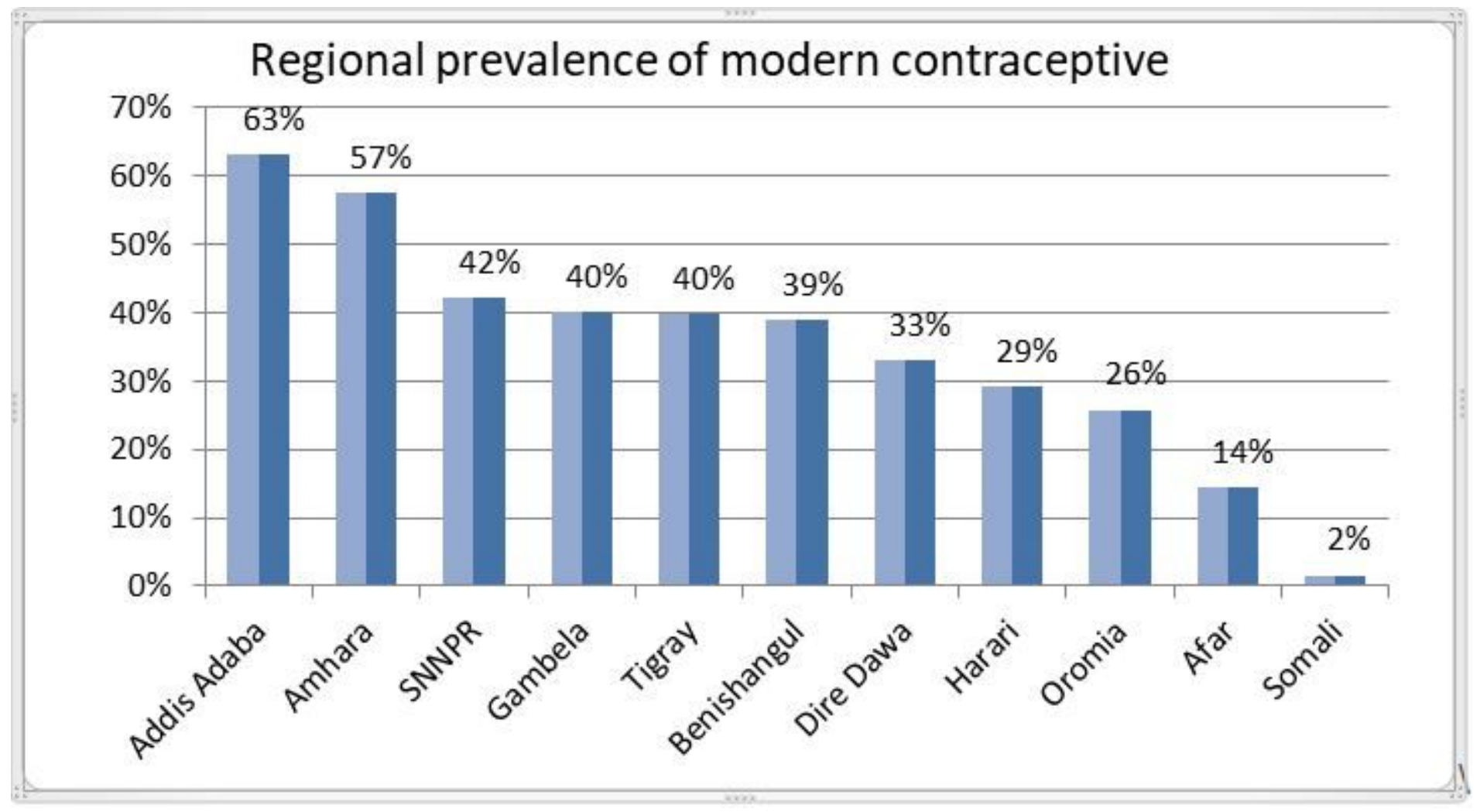

Figure 1

Regional of prevalence of modern contraceptive utilization among young married women 


\section{Spatial Autocorrelation Report}

Moran's Index: 0.454807

z-score: 5.269765

p-value: 0.000000

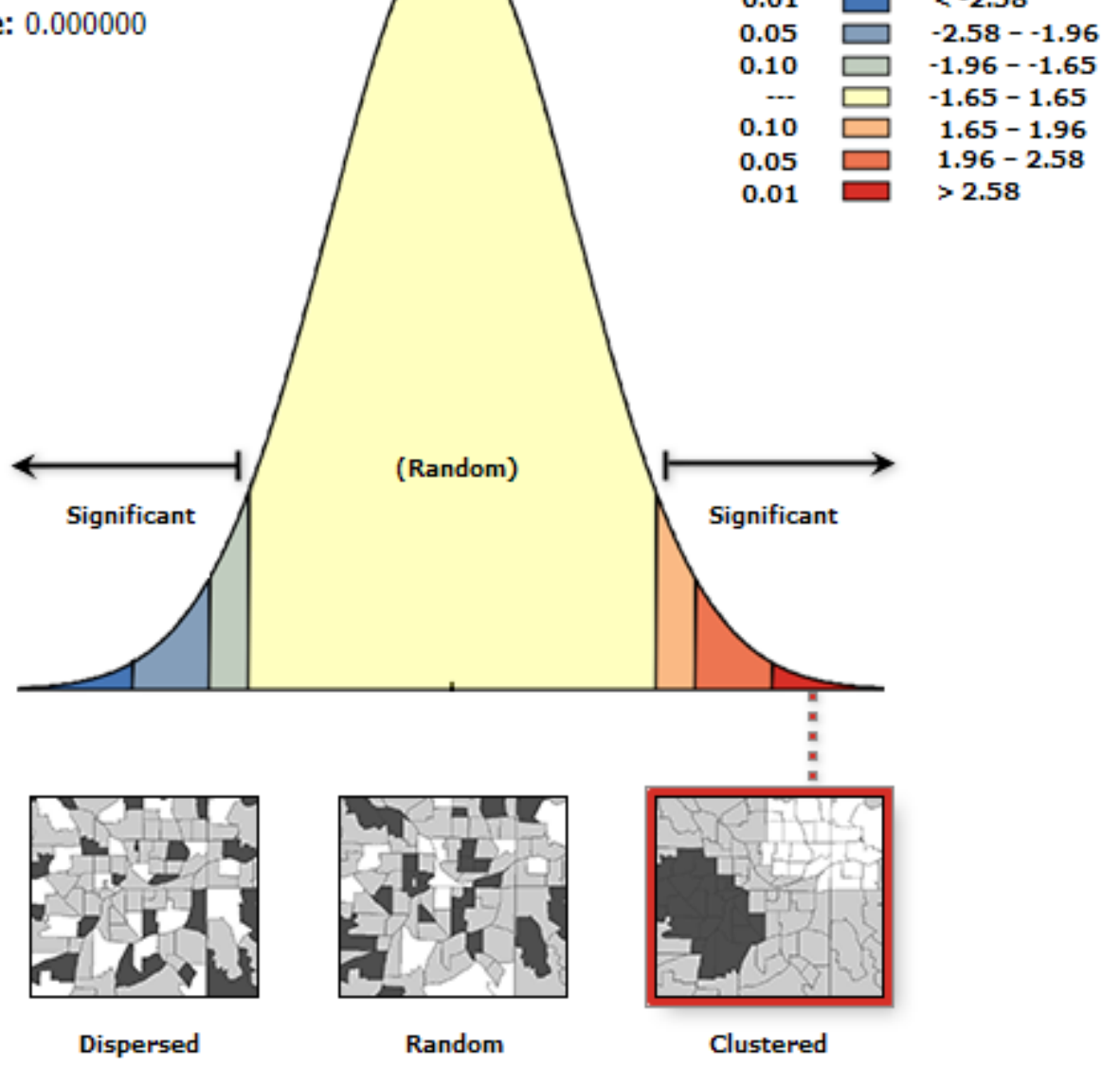

Given the $z$-score of 5.269764611 , there is a less than $1 \%$ likelihood that this clustered pattern could be the result of random chance.

Figure 2

Spatial autocorrelation of modern contraceptive utilization among young married women 


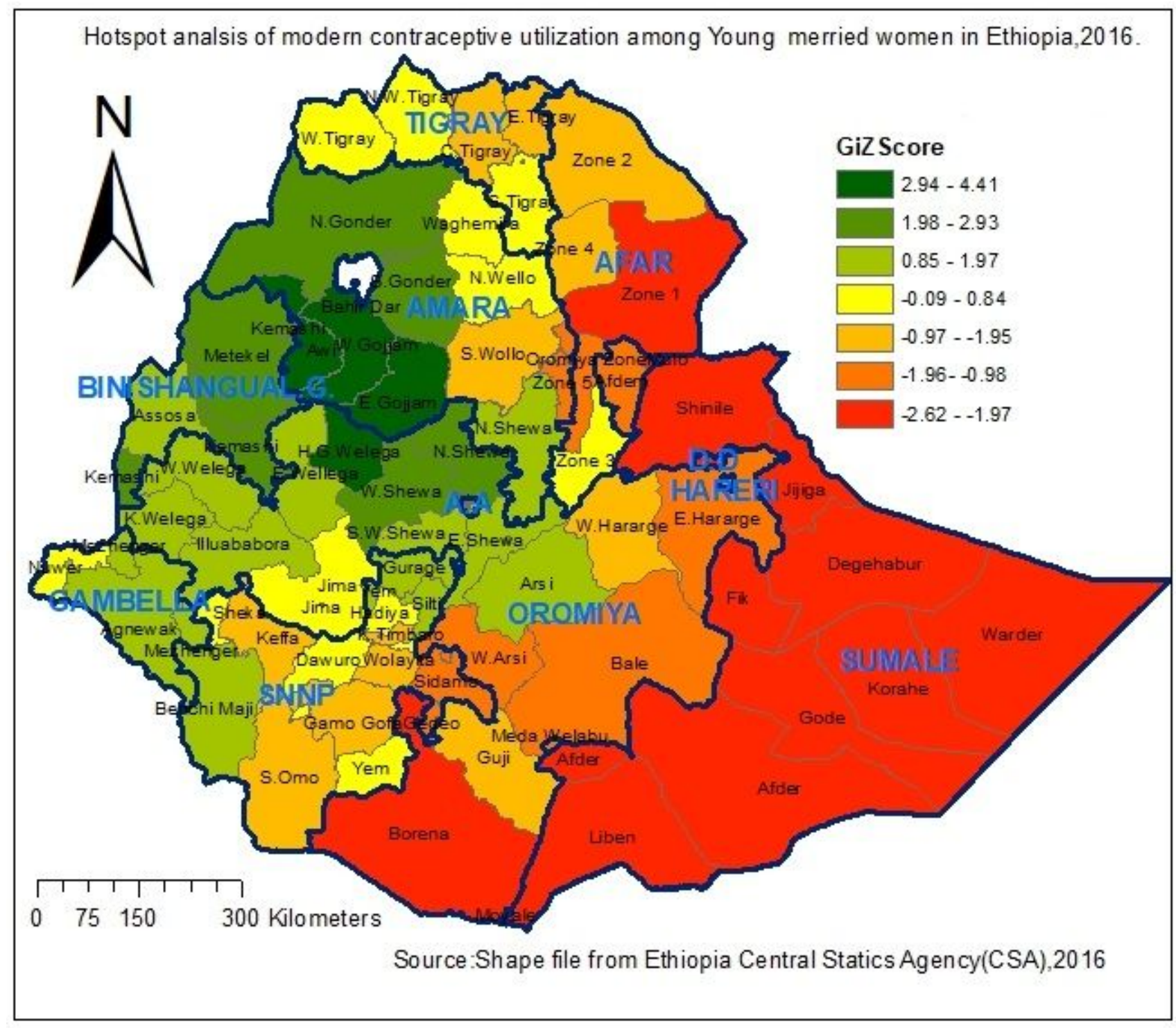

\section{Figure 3}

Hotspot analysis of modern contraceptive utilization among young married women 


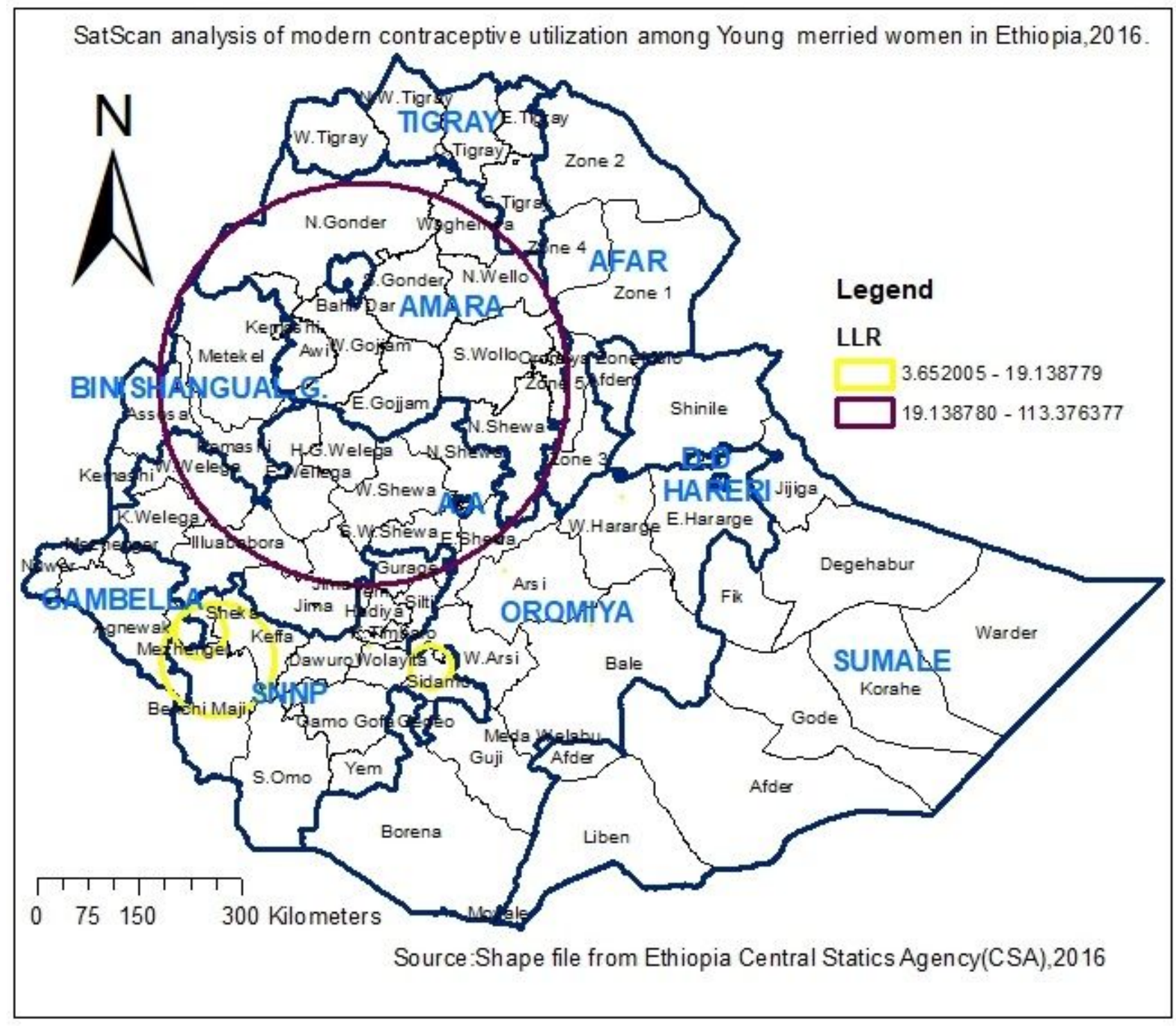

Figure 4

SatScan analysis of modern contraceptive among young married women 